\title{
THE EFFECTS OF FINANCIAL KNOWLEDGE, SOCIALISATION, ATTITUDE AND SKILL ON MALAYSIAN SMES' PERFORMANCE
}

\author{
Dzuljastri Abdul Razak1,* and Hanudin Amin² \\ ${ }^{1}$ Kulliyyah of Economics and Management Sciences, International Islamic University Malaysia (IIUM) \\ ${ }^{2}$ Labuan Faculty of International Finance, Universiti Malaysia Sabah (UMS)
}

ABSTRACT - Though considered trivial, small and medium enterprises (SMEs) were one of the contributing factors for Malaysia economy growth. Besides providing employment, SMEs also provide an improved integration to ensure other businesses survive in the long run. Thus, the present study examined the contributing factors to explain SMEs' performance, be it high or negative. Drawing upon the financial literacy theory, this study proposed a model of factors to examine the effects of financial knowledge, socialisation, attitude and skill on the performance of SMEs industry in Malaysia. The model was examined using owners of the SMEs drawn from 413 respondents collected in West Malaysia. Our results suggested that the said indicators were instrumental in determining the performance, and attitude was also essential as a mediator as discovered in our PLS analyses. In practice, however, this study jacked up a new understanding of why SMEs' performance is of importance, and the survey approach in measuring the performance is nothing but important. Our findings provide an insight for owners of SMEs to manage their businesses, where financial knowledge, financial socialisation, financial attitude and financial skill are brought into play.
ARTICLE HISTORY

Received: $19-9-2020$

Accepted: $3-12-2020$

\section{KEYWORDS}

Financial Knowledge, Financial Socialisation, Financial Attitude, Financial Skill, Malaysia, SMES

\section{INTRODUCTION}

Small and Medium Enterprises (SMEs) have been essential as a force in advancing economic activities in Malaysia ranging from the fulfilment of consumers' demand for products and services to the provision of employment to local folks. There is no universally accepted definition for SMEs as it might be different from one country to another in terms of employment, revenue, and total asset. According to the National SME Development Council (NSDC) (2013), SMEs can be defined according to sectors. As for manufacturing, the sales turnover is not exceeding RM50 million or fulltime employees are not exceeding 200. As for services and other sectors, the sales turnover is not exceeding RM20 million or full-time employees are not exceeding 75 employees. A business is deemed as an SME when it meets either one of these criteria, namely sales turnover or full-time employees, whichever is lower. Regardless of this definition, SMEs are collectively significant contributors in producing improved productivity of productions as well as complementing the large businesses' presence and so do government-linked companies.

This topic is important to explore in three ways. Firstly, the performance of SMEs in Malaysia is not guaranteed in which some fail whilst others succeed - explaining there are gaps in advancing business strategies to improve their businesses. One of the issues which are equally critical to contribute to the performance is financial literacy. We might notice some SMEs are not considering educating their staff as this can increase their operating costs at the expense of operating profit. Hence, studying this topic will offer new insight into understanding SMEs' eagerness in promoting financial literacy and for that, a yardstick needs to be developed. Secondly, SMEs are instrumental in generating new employment outlets in the area that they operate with (Neagu, 2016). In other words, SMEs are critically important for maintaining social stability in terms of safeguarding the purchasing powers of folks. SMEs are important in maintaining an economic balance and interest of all stakeholders involved. Thirdly, SMEs are typically managed by a middle-class group, which to a certain extent have lesser experience in lending from financial institutions due to poor financial records, which is linked to reduced financial literacy.

Role of the knowledge-based resources in promoting sustainability in SMEs is currently a topic of debate. Financial literacy has been identified as a vital knowledge resource for financial decision making, but insufficient attention has been given to how SMEs' financial literacy affects their sustainability. All the sets of skills that a SMEs owner needs to know include how far and is their level of knowledge or skill is sufficient to promote growth among SMEs or in their own business. Moreover, poor financial decisions are a result of a low level of financial literacy. People with low levels of financial literacy suffer a lack of knowledge at the very beginning of their life or the beginning of their business. As evidence, it will result in poor decision-making in financial planning or financial matters on the financial market. 
Against this backdrop, the present study is aimed at explaining the effects of financial knowledge, socialisation, attitude, and skill on Malaysian SMEs' performance. Strengthening the effects of these factors can economically and socially benefit all stakeholders involved, where the importance of financial literacy is brought into play.

\section{LITERATURE REVIEW}

\section{Financial knowledge}

Business owners and managers are the main key stakeholders in running the business, where they have a big role in determining the success of the business. Hence, knowing finance can influence the business owner and manager to make decisions for the company. In other words, they manage to identify the right way to make a financial decision, aware of the business cycles, and alert about financial products that suit the business.

Chen and Volpe (1998) examined 924 students from multiple universities across the country to examine college students' knowledge of personal finance. This study found out that college students are not knowledgeable about personal finance - implying the incompetency will limit their ability to make informed financial decisions. Chen and Volpe (1998) asserted that the lack of education has resulted in serious financial illiteracy found in the American public. Of course, financial knowledge is very essential in the real world. Without adequate knowledge, they are more likely to make mistakes in financial decisions in mortgages, loans, and others. Unlike Chen and Volpe (1998), a study by Jorgensen and Savla (2010) examined the effect of parental influence on the financial literacy of young adults using 420 college students as the sample. The study found out that parental influence has a direct and moderately significant influence on financial attitude, did not have an effect on financial knowledge, and has an indirect and moderately significant influence on financial behaviour, mediated through financial attitude.

In contrast, Agnew and Cameron-Agnew's (2015) study considered gender influences in explaining financial literacy. It was hypothesised that financial education (termed as education) can make a difference in financial literacy. This work overlooked the significance of Grable and Joo's (1998) work on financial education. This study managed to expose a substantial effect on financial knowledge on financial literacy. It is out of the fact that financial knowledge can build a cogent skill and competence to individuals that form a better perspective of financial literacy. A formal financial course can lead to a disposition of belief of being balanced in personal finance management (Agnew and Cameron-Agnew, 2015). Yet, the effect of financial knowledge on financial performance is somewhat unexplored due to different research paradigm that existed in the studies examined. The present study expects to contribute to the literature by developing a link between financial knowledge and financial performance. Hence,

\section{$\mathrm{H}_{1}$ : Financial knowledge has a significant effect on financial performance}

\section{Financial socialisation agents}

Several factors influence the decisions of business owners and managers. One of them is the social norm. It is where the culture can affect the method in the running of the business. The social agent can come from families, friends, and even social media. Against this backdrop, the term financial socialisation agent is viewed as interactions among transacting parties concerning financial decisions on consumption and spending. As such, financial socialisation agents can be defined as an interaction between one particular individual, acts as an agent with other individuals on financial transactions. Likewise, a study by Jorgensen and Savla (2010) tested the effect of parent interaction concerning financial matters. Young adults need to have the basic knowledge and skill to make inferences, and these attributes can only be made somewhat through family member interactions. Parents are experienced with financial matters and the knowledge of their children on financial matters can be improved if the interaction is effectively done through clear and precise messages communicated verbally and sometimes through written notes.

A study by Hira et al. (2013) examined financial socialisation's impact on investment orientation and household net worth. Parents' influence emerged as a relevant socialisation agent of investors, influencing investment regularity, and household net worth above and beyond demographic characteristics of investors. The finding demonstrated by Hira $e t$ al. (2013) pointed out the importance of parents' inclusion when promoting investment programmes. Similarly, a work by Agnew and Cameron-Agnew (2015) found out that there was no significant effect of financial socialisation agents on financial literacy, signifying the variable has a poor role in the formation of financial literacy, perhaps it depends on the contents to what needed in socialisation. The findings of this work suggested that financial socialisation in the home may be subject to a gender bias, which over time contributes to differential financial literacy knowledge levels between the genders. This work was somehow extended a notion of Danes (1994), only the context and findings that can make a difference. Though these studies were not discussing the direct effect of financial socialisation on the financial performance of SMEs, its extension on SMEs was expected to contribute to the body of knowledge. In response to this belief, we propose $\mathrm{H}_{2}$ as:

\section{$\mathrm{H}_{2}$ : Financial socialisation agents have a significant effect on financial performance}

\section{Financial attitude}

Financial attitude is the way a business owner and manager manage their finance based on their behaviour, age, gender, and experience. Males are commonly well-managed in investment whereas women are more driven towards the relationship. Following Jorgensen and Savla (2010), the effect of financial attitude on financial literacy is found to be 
significant which implies the higher the extent of financial attitude, the better is the financial literacy and vice versa. Besides, several studies have discovered that one's attitude towards finance is linked with their spending habits, financial practices, and behaviours (Hayhoe et al., 1999). Though voluminous tutelage programmes are battered to assist individuals in obtaining efficient personal finance management, only a few have changed their attitudes toward improved personal finance. This is related to poor financial matters' involvement that creates rejection to proper learning of financial practices. It is also caused by poor reading on a financial matter that jacks up a level of ignorance to practice wise financial decisions. Futhermore, Agnew and Cameron-Agnew (2015) found that attitude towards money can have a significant role in shaping how good one is in managing and shaping the belief of money in every spending taken and consumption. It is worth noting that a financial attitude is positive when one believes that money has a high value in one's spending and consumption. A work by Kim (2003), for instance, argued that money that serves as a safety tool can trigger better money management and thus, building up a cogent perspective of literacy on it. Given these assertions, we propose the following hypothesis to contribute to the body of knowledge:

\section{$\mathrm{H}_{3}$ : Financial attitude has a significant effect on financial performance}

Likewise, we also expect that financial attitude extends its role not only as a predictor for financial literacy but also as a dependent variable, and to be predicted by financial knowledge and financial socialisation agents. Limited studies were documented when financial literacy comes into play. For this purpose, we extended some relevant studies (Amin et al., 2009; Lada et al., 2009). Amin et al. (2009) reported a significant result of people's influence on attitude, mainly in the case of Islamic accounting enrolment. Lada et al. (2009) also reported a significant effect of people's influence on attitude. Together, these two works provided a departure in which financial socialisation agents are influential in determining one's financial attitude. Referring to financial knowledge, there is a shred of evidence in the literature signifying the relationship between one's knowledge and attitude. For instance, Aertsens et al. (2011) discovered the significant role of knowledge in determining one's attitude towards organic foods. On the same note, Manika et al. (2018) also found a noteworthy role in knowledge and attitude, mainly in the context of one's attitude towards the website. It is anticipated to extend these findings to our contexts. In all, we propose the following hypotheses:

$\mathrm{H}_{4}$ : Financial knowledge has a significant effect on financial attitude towards financial performance

$\mathrm{H}_{5}$ : Financial socialisation agents have a significant effect on financial attitude towards financial performance

$\mathrm{H}_{6}$ : Financial skill has a significant effect on financial attitude towards financial performance

We also intend to evaluate whether financial attitude can play a role as a mediator in the current context. In this work, a mediating variable is defined as "how" significant the relationship exists between one variable and an outcome factor when a third variable that is a mediator is included. The higher the extent of financial attitude, the better is the financial literacy. Such a relationship, however, does not prove by any works in financial literacy. An attitude has been instrumental in consumer research and mainly in the growing field of Islamic banking consumers. Two works but are not limited to Haque (2010) and Abdul-Razak and Abduh (2012) provide a departure. In this study, however, the role of attitude will be heightened not only as an independent factor but also as a dependent'. Two important works in Malaysia but are not confined to M-Yasin et al. (2009) and Ismail et al. (2007) provide a piece of evidence that attitude is proven to be a significant mediator in various relationships in consumer research. Based on this assertion, we propose the following hypotheses:

$\mathrm{H}_{7}$ : Financial attitude works as a mediating factor for the relationship between financial knowledge and financial performance

$\mathrm{H}_{8}$ : Financial attitude works as a mediating factor for the relationship between financial socialisation agents and financial performance

$\mathrm{H}_{9}$ : Financial attitude works as a mediating factor for the relationship between financial skill and financial performance

\section{Financial skill}

Financial skills need to be educated among SMEs to sustain the business. Previous studies reported that financial skill is directly correlated to financial performance which defined that financial skill is significant too for managing business finance (Miller et al., 2009). Following Miller et al. (2009), financial skills are linked to the use of financial products that enable investors to evaluate financial products like credit financing and current accounts, to make sound financial decisions. The ability to make informed financial decisions is a manifestation of inefficient allocation of financial resources that translates into improved financial stability, as addressed by Klapper et al. (2013). Lack of skills can cause the business to fail like what had happened to African according to an article written by Eniola and Entebeng (2017). Their SMEs had a terrible situation where they cannot run a business properly due to lack of skills and the failure rate is 85 out of every 100. Following Kimunduu et al. (2016), financial skill refers to the person's competencies in financial knowledge pertinent to budgeting, bookkeeping, saving, entrepreneurial, and banking services skills. On the same note, Kizza (2019) viewed financial skills as a person's competencies in budgeting, financial analysis, and credit management skills, extending the Kimunduu et al. (2016) research paradigm. This denotes that SMEs' 
performance is significantly improved when its employees are equipped with financial skills that lead to improved financial decisions. Thus.

\section{$\mathrm{H}_{10}$ : Financial skill has a significant effect on financial performance}

\section{Financial performance}

It is defined as a subjective measure of how well SMEs can use their assets to generate revenues - implying the overall financial health of the fiscal operation. In other words, it is an SME's success, condition, and compliance in generating profit exceeding expenses. Studies from extant pieces of literature generally agreed that financial performance is important for SMEs to maintain their presence and survival in the long run (Greenspan, 2002; Kizza, 2019). Grrenspan (2002) asserted that the financial performance of a given firm is associated with the financial skills owned by the business, the staff, and the management due to effective financial decisions in budgeting, savings plan, credit financing, and strategic investment decisions. Kizza (2019) who extended Greenspan's (2002) idea, concluded that financial performance is sourced from improved practices of financial literacy in companies. Financial literacy enables businesses to improve financial performance through effective allocation of financial resources at ensuring the sustainability of business operation and competitiveness (Kizza, 2019). Hence, this study asserts that financial performance is important for SMEs including in Malaysia's case. Improved SMEs' contribution can be found through the allocation of employment to a community that helps reduce the poverty rate. On the same note, SMEs allow better production that meets the demand of the public at large in terms of products and services, and without them, the ummah well-being tends to be tarnished, at least.

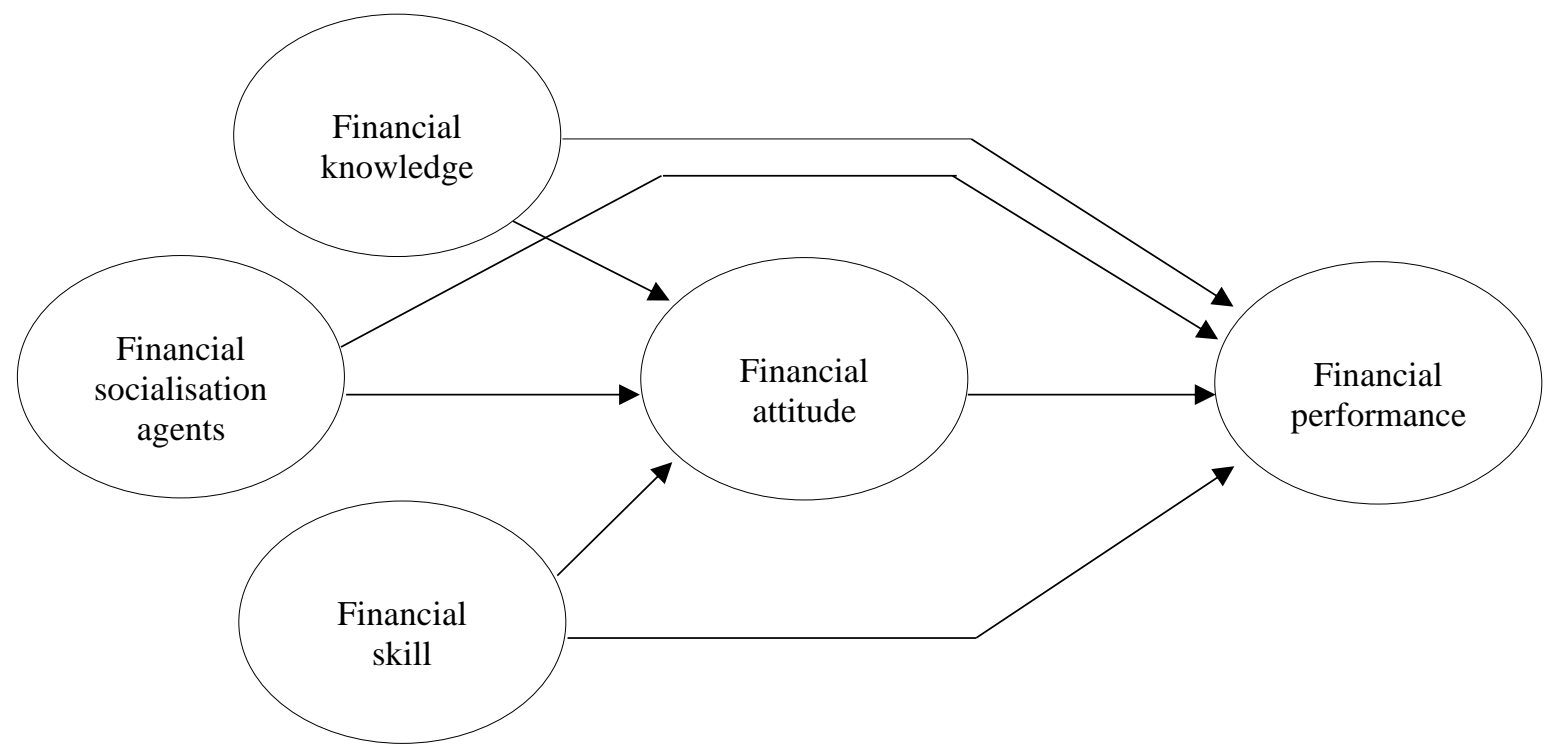

Given our literature analyses as noted above, we then develop our research model as follows:

Figure 1: The research model

Based on Figure 1, the model is best described as follows:

$$
\mathrm{FP}_{\mathrm{i}}=\alpha+\sum_{K=1}^{3} \beta_{\kappa} \mathrm{FK}_{\mathrm{ki}}+\sum_{L=1}^{3} \gamma_{\ell \mathrm{FSA}_{\ell \mathrm{i}}}+\sum_{M=1}^{3} \psi_{\mathrm{M} \mathrm{FAM}}+\sum_{O=1}^{3} \eta_{\mathrm{M} \mathrm{FSo}}+\varepsilon_{\mathrm{i}}
$$

Where:

$\begin{array}{lll}\mathrm{FP}_{\mathrm{i}} & = & \text { Financial performance } \\ \mathrm{FK} & = & \text { Financial knowledge } \\ \mathrm{FSA} & = & \text { Financial socialisation agents } \\ \mathrm{FA} & = & \text { Financial attitude } \\ \mathrm{FS} & = & \text { Financial skill }\end{array}$

Equation (1) indicates that the SMEs' performance could be influenced by financial knowledge, financial socialisation agents, financial attitude, and financial skill. FPi is a vector of the SMEs' performance. FKi is a vector of 
financial knowledge. FSAi is a vector of financial socialisation agents, FAi is a vector of financial attitude and FSi is a vector of financial skill.

Besides, we also consider financial attitude (FA) as a dependent variable, which is influenced by three variables namely financial knowledge, financial socialisation agents, and financial skill. The model of this is best described as follows:

$$
\mathrm{FA}_{\mathrm{i}}=\alpha+\sum_{K=1}^{3} \beta_{\kappa} \mathrm{FK}_{\kappa \mathrm{i}}+\sum_{L=1}^{3} \gamma_{\ell} \mathrm{FSA}_{\ell \mathrm{i}}+\sum_{O=1}^{3} \eta_{\mathrm{M} \mathrm{FSo}_{\mathrm{i}}}+\varepsilon_{\mathrm{i}}
$$

Where:

$\begin{array}{lll}\text { FA }_{\mathrm{i}} & = & \text { Financial attitude } \\ \mathrm{FK} & = & \text { Financial knowledge } \\ \mathrm{FSA} & = & \text { Financial socialisation agents } \\ \mathrm{FS} & = & \text { Financial skill }\end{array}$

Equation (2) indicates that the SMEs' financial attitude could be influenced by financial knowledge, financial socialisation agents, and financial skill. $F A i$ is a vector of the SMEs' financial attitude. $F K i$ is a vector of financial knowledge. FSAi is a vector of financial socialisation agents and FSi is a vector of financial skill.

\section{METHODOLOGY}

\section{Sample}

The unit analysis of this study is SME in West Malaysia. Data were collected among the owners of the SMEs in West Malaysia in which a total of 450 questionnaires were provided for actual fieldwork. For actual fieldwork, we distributed the questionnaires using the judgmental sampling method in which two criteria were considered to opt the SMEs. The details are provided below.

- First, the SMEs selected are generally exposed to financial literacy issues and their links to improving their companies' productivity; and

- Second, the SMEs selected intend to improve financial literacy among their employees to improve the overall productivity of their operating profits.

Following Hair et al.'s (2006) approach, our sample size was determined. In more detail, Hair et al. (2006) suggested the minimum requirement for sample size is to have at least five participants per item. In our case, four variables involved that come up with three battery items each, denoting a minimum sample size of 60 (given $4 * 3 * 5=60$ ). Our actual sample size was 413 respondents, exceeding the minimum requirement. Specifically, we also considered Freedman et al. (2002) to determine sample size, based on this formula:

$$
\sqrt{\mu}=t x \frac{s}{e}
$$

In this formula, $\mu$ is denoted standard deviation, $e$ is the margin of error and tx is the value of $t$-statistic. The tx is based on $95 \%$, hence we consider 1.96 , and the calculation as follows is considered:

$$
\begin{gathered}
\sigma=0.5 \\
e=0.06
\end{gathered}
$$

We keep $6 \%$ of the margin of error in the above formula. The final computation to determine the sample size is as follows:

$$
\begin{gathered}
\sqrt{\mu}=\frac{1.96 * 0.5}{0.06} \\
\mu=266
\end{gathered}
$$

This method in determining sample size has been proven appropriate in the case where non-probability sampling is brought into play (See, Ateed and Ur Rehman, 2020). Our sample size exceeds this threshold value, implying it is sufficient and deems appropriate to meet our research objective. 
Specifically, we obtained a total of $40.9 \%$ male and $59.1 \%$ female, $72.2 \%$ of the respondents are mostly Malay. Most of the respondents have a range of 5 to 50 employees (48.4\%) followed by less than 5 employees $(44.1 \%)$. The details are presented in Table 1.

Table 1: Demographic

\begin{tabular}{llll}
\hline No. & Item & Description & Percentile \\
\hline 1. & Gender & Male & $244(59.1 \%)$ \\
& & Female & $169(40.9 \%)$ \\
2. & Employees' number & Less than 5 & $182(44.1 \%)$ \\
& & 5 to 50 & $200(48.4 \%)$ \\
& & 51 to 100 & $24(5.8 \%)$ \\
& & 101 to 150 & $2(.5 \%)$ \\
& & 151 to 200 & $5(1.2 \%)$ \\
3. & Ethnicity & Malay & $298(72.2 \%)$ \\
& & Chinese & $48(11.6 \%)$ \\
& & Indian & $46(11.1 \%)$ \\
& & Other & $21(5.1 \%)$ \\
\hline
\end{tabular}

\section{Measures}

All measurement items used in the present study were adapted from earlier works related to the factors under contemplation. We employed Churchill Jr.'s (1979) approach to generating research items. As for all items, we employed the same 5-Likert scale in which 1 defines strongly disagree, 2 defines disagree, 3 defines slightly agree, 4 defines strongly agree, and lastly 5 indicates strongly agree.

- The battery items for financial knowledge were adapted from Chen and Volpe (1998) and Agnew and Cameron-Agnew (2015);

- Furthermore, the measurement for financial socialisation agents was determined using three items adapted from Jorgensen and Savla (2010) and Hira et al. (2013);

- On the same note, the battery items for financial attitude were adapted from Jorgensen and Savla (2010) and Kim (2003);

- $\quad$ The battery items for financial skill were adapted from Kizza (2019); and

- The battery items for financial performance were adapted from Kizza (2019).

A pilot test involving 40 different respondents was conducted among the owners of the SMEs. This test was performed to evaluate the reliability of dependent and independent variables. Through the exercise, we found out that the respondents chosen had a familiarity with the research instrument without any difficulty to understand the questions or items asked. We finally improved the research instrument by considering the format and layout for the final survey or actual survey.

\section{FINDINGS AND DISCUSSION}

\section{Measurement model}

Following Chin's (2010), the two-stage approach was used in analysing the data obtained. In the first stage, we performed various analyses to capture the measurement model, whilst in the second phase, we were expected to meet the research objective. All factor loadings as presented in Table 2, pointing out that their dimensions were greater than the recommended value of 0.7 , approving discriminant validity. The dimensions tested were loaded higher in their hypothesised factors.

Table 2: Factor analysis

\begin{tabular}{llllll}
\hline Battery items & FA & FK & FP & FSA & FS \\
\hline FA1 & 0.783 & 0.486 & 0.318 & 0.195 & 0.460 \\
FA2 & 0.864 & 0.410 & 0.433 & 0.249 & 0.558 \\
FA3 & 0.867 & 0.404 & 0.429 & 0.236 & 0.360 \\
FK1 & 0.416 & 0.769 & 0.361 & 0.188 & 0.435 \\
FK2 & 0.456 & 0.814 & 0.428 & 0.250 & 0.395 \\
FK3 & 0.311 & 0.766 & 0.348 & 0.289 & 0.274 \\
FP1 & 0.410 & 0.454 & 0.875 & 0.261 & 0.479
\end{tabular}




\begin{tabular}{llllll}
\hline Battery items & FA & FK & FP & FSA & FS \\
\hline FP2 & 0.399 & 0.437 & 0.869 & 0.283 & 0.440 \\
FP3 & 0.426 & 0.376 & 0.864 & 0.251 & 0.439 \\
FSA1 & 0.167 & 0.184 & 0.230 & 0.719 & 0.184 \\
FSA2 & 0.222 & 0.250 & 0.268 & 0.871 & 0.221 \\
FSA3 & 0.241 & 0.275 & 0.213 & 0.736 & 0.225 \\
FS1 & 0.561 & 0.412 & 0.354 & 0.213 & 0.837 \\
FS2 & 0.313 & 0.383 & 0.388 & 0.163 & 0.844 \\
FS3 & 0.504 & 0.390 & 0.548 & 0.296 & 0.809 \\
\hline
\end{tabular}

Note: FA = Financial attitude, FK = Financial knowledge, FP = Financial Performance, FSA = Financial Socialisation, FS = Financial Skill

Likewise, based on Table 3, we also reported the outcomes relevant to AVE, composite reliability, and Cronbach's alpha. Following Lee and Kozar (2008), all reported CR values were exceeding the threshold of 0.7. Besides CR values, we managed to attain acceptable AVE values for all constructs and they were found to be greater than the minimum value of 0.5 to support convergent validity. The Cronbach's alpha values were also acceptable, higher than the recommended value of 0.6 for internal consistency.

Table 3: Reliability and AVE

\begin{tabular}{lllll}
\hline Variable & AVE & Composite Reliability & $R^{2}$ & Cronbach's Alpha \\
\hline FA & 0.704 & 0.877 & 0.504 & 0.790 \\
FK & 0.614 & 0.827 & 0.000 & 0.689 \\
FP & 0.755 & 0.903 & 0.366 & 0.838 \\
FS & 0.688 & 0.869 & 0.000 & 0.774 \\
FSA & 0.606 & 0.821 & 0.000 & 0.670 \\
\hline
\end{tabular}

Note: FA = Financial attitude, FK = Financial knowledge, FP = Financial Performance, FSA = Financial

Socialisation, FS = Financial Skill

Given a Fornell and Larcker's (1981) reference, we conducted a discriminant validity test, inferring the square root of the AVE from the construct is larger than the association shared between that constructs and others in the model. Table 4 reports the square root of the AVE for all constructs and the outcomes acceptable $(>0.7)$, meeting discriminant validity.

Table 4: Discriminant validity

\begin{tabular}{lrrrrr}
\hline Variable & FA & FK & FP & FS & FSA \\
\hline FA & 0.839 & & & & \\
FK & 0.511 & 0.784 & & & \\
FP & 0.473 & 0.487 & 0.869 & & \\
FS & 0.674 & 0.476 & 0.522 & 0.830 & \\
FSA & 0.271 & 0.306 & 0.305 & 0.271 & 0.778 \\
\hline
\end{tabular}

Note: FA = Financial attitude, FK = Financial knowledge, FP = Financial Performance, FSA = Financial Socialisation, FS = Financial Skill

\section{Structural model}

The effects of the factors under contemplation are analysed using PLS. Following Hulland (1999), the variance explained for financial performance is $36.6 \%$ explained to be acceptable greater than the recommended value of $20 \%$, implying financial attitude, financial knowledge, financial socialisation, and financial skill are essential in the formation of an SME performance.

Table 5: Path analysis (Regression)

\begin{tabular}{llll}
\hline Pathway & Beta & $t$-value & Supported \\
\hline FA $\rightarrow$ FP & 0.181 & 3.390 & Yes \\
FK $\rightarrow$ FA & 0.166 & 4.137 & Yes
\end{tabular}




\begin{tabular}{llll}
\hline Pathway & Beta & $t$-value & Supported \\
\hline FK $\rightarrow$ FP & 0.249 & 5.041 & Yes \\
FS $\rightarrow$ FA & 0.606 & 15.074 & Yes \\
FS $\rightarrow$ FP & 0.247 & 4.226 & Yes \\
FSA $\rightarrow$ FA & 0.044 & 1.328 & No \\
FSA $\rightarrow$ FP & 0.116 & 2.245 & Yes \\
\hline
\end{tabular}

Note: FA = Financial attitude, FK = Financial knowledge, FP = Financial Performance, FSA = Financial Socialisation, FS = Financial Skill

The results obtained as reported in Table 5 suggested that financial skill has the highest influence on financial performance $(\beta=0.606$ and $t=15.074)$ followed by financial knowledge $(\beta=0.249$ and $t=5.041)$ and the last ranked but considered instrumental is financial socialisation. The reasons why the financial skill appeared to be highly important are two-fold. First, financial skill is essential to uphold financial practices and important to maintain financial stability within SMEs. Second, financial skill is important as it equips managers with accounting knowledge to manage money effectively.

\section{Post hoc analyses}

As presented in Table 5, financial knowledge relates significantly to attitude, and in turn, attitude relates to financial performance. Similarly, financial socialisation affects attitude and in turn, the latter influences performance. On the same note, financial skill is found to have an impact on attitude, and in turn, attitude influences performance. These results signify the mediating effects of attitude on the relationship between the said factors examined and the financial performance. To test these mediating effects, we followed Preacher and Hayes' (2008) procedure. It suggested that the mediating effects can occur when the bootstrapping results of the lower level (LL) and the upper level (UL) do not straddle a 0 in between to conclude that there is mediation.

Table 6: Mediation testing

\begin{tabular}{llllll}
\hline $\begin{array}{l}\text { Indirect } \\
\text { effect }\end{array}$ & Estimate $(\beta)$ & Standard Error $(\mathrm{SE})$ & $t$-values & \multicolumn{2}{c}{$\begin{array}{l}\text { Percentile bootstrap } \\
\text { confidence interval }\end{array}$} \\
\cline { 4 - 6 } & & $05 \%$ & Lower & Upper \\
\hline$\beta_{1}=a_{1} b_{x}$ & 0.030 & 0.053 & 2.624 & 0.052 & 0.008 \\
$\beta_{2}=a_{2} b_{x}$ & 0.008 & 0.006 & 1.173 & 0.021 & -0.005 \\
$\beta_{3}=a_{3} b_{x}$ & 0.109 & 0.033 & 3.284 & 0.175 & 0.077 \\
\hline
\end{tabular}

Notes. $\beta_{1}=\mathrm{FK} \rightarrow \mathrm{FA} \rightarrow \mathrm{FP}, \beta_{2}=\mathrm{FSA} \rightarrow \mathrm{FA} \rightarrow \mathrm{FP}$, and $\beta_{3}=\mathrm{FS} \rightarrow \mathrm{FA} \rightarrow \mathrm{FP}$

The bootstrapping analysis in Table 6 shows that $\beta_{1}=0.030$, and $\beta_{3}=0.109$ are significant with $t$-values of 2.624 and 3.284, respectively. Further examination indicates that CI for estimation of indirect effects did not straddle across zero. Thus, this finding suggested mediation effects for financial knowledge and financial skill. Financial attitude, however, does not mediate the relationship between financial socialisation and financial performance.

\section{RESEARCH CONTRIBUTIONS}

\section{Theoretical contributions}

This study contributes to the body of knowledge in several ways and we limited them to three. Firstly, this study defined financial performance from the context of financial literacy involving financial knowledge, financial socialisation agents, financial skill, and financial attitude, which in turn can affect financial performance significantly. Secondly, this study hypothesised that financial knowledge, financial socialisation agents, and financial skill are impacting financial attitude, which in turn determine financial performance. Thirdly, this study found out that financial attitude did not only serve as an independent variable in explaining financial performance but also served as a significant mediating variable. Financial attitude mediates the relationships between financial knowledge, financial skill and financial performance and the results are significant. Fourthly, this study explained financial performance from the context of financial literacy among Malaysian SMEs, where the business owners' viewpoints are brought into play.

\section{Methodological contributions}

Our battery items were further improved from the existing studies on financial literacy and financial performance. Since the contexts were not in Malaysia, we conducted a pilot test to validate our battery items reflecting the Malaysians' reality and for that, the conduct of an empirical survey can be done to secure significant findings. Previous studies developed their measurement scales from other contexts and this leads us to modify the battery items, where the 
adjustment was conducted to ensure their relevance and significance in Malaysia context. Besides, we modified three battery items each to represent their constructs under contemplation, and our factor analysis suggested that all three items had good validity and discriminant validity too. This study also suggested as noted earlier, treating financial attitude as not only a variable that directly affects financial performance but also as a mediator. This has improved further our understanding pertinent to the factors that affect financial performance.

\section{Practical contributions}

The results obtained can guide managers whose objective is to promote SMEs' financial performance through financial literacy determined by financial knowledge, financial socialisation agents, financial attitude, and financial skill. This study contributed practically in several ways. Firstly, it has been shown in this study that these factors were the dominant predictors of SMEs' financial performance. Thus, decision-makers might consider, for instance, that financial education is aimed at strengthening the financial performance in which indoor training can be conducted to improve the knowledge workers' paradigm. Secondly, even though their influence varies from one to another, financial skill appeared first in rank, and significant variable that facilitates the financial performed should be considered with cautious by business owners by formulating skills that are related to their businesses, which can help improve their profitability. Thirdly, this study indicates that to be financially improved, the business owners, at least, should possess financial knowledge, a good attitude, strengthened financial skill, and have abilities to communicate their intended financial skills to their staff to ensure the latter can perform their duties successfully. In sum, the results obtained in this study suggested that managers might increase their businesses by promoting healthy financial literacy of SMEs and establishing spur strategies.

\section{CONCLUSION}

Understanding why SMEs perform or not has been one of the most challenging issues in SME research field due to the difficulty to understand specific factors leading to success and failure. Different SMEs require a different set of attributes to justify their performance and may explain that not all factors determine success. In this line of thought, the present study examined the effects of some significant determinants that influence SMEs' financial performance. Financial skills owned by SMEs' employees generally appear as the first factor that determines the performance followed by other attributes. Financial attitude, financial knowledge, and financial socialisation are also instrumental in determining financial performance.

The main motivation behind this study lies in the additional emphasis on the attention and the research of the SMEs in Malaysia. Therefore, this research examines the factors that contribute to the success of this sector in the economy. From the results and findings, it is obvious from this research that SMEs in Malaysia are not only "side dishes" in the economy of the country, but rather, they are one of the core driving forces and a very crucial sector in the financial and business world. This study has shown the positive impact SMEs are contributing to the overall well-being of the community.

Despite these fruitful outcomes, this study has some drawbacks. To guide future research, we present two research limitations. Firstly, this study considered the general term of SMEs in West Malaysia without explaining the specificity issue like types of business and services. Future studies may consider the inclusion of this attribute to extend the findings. Second, this study only considered five factors, which may explain why $R^{2}$ is less than $50 \%$. Future research should consider new variables for extensions and generalisations.

\section{REFERENCES}

Abdul Razak, D., \& Abduh, M. (2012). Customers' attitude towards diminishing partnership home financing in Islamic banking. American Journal of Applied Science, 9(4), 593-599.

Aertsens, J., Mondelaers, K., Verbeke, W., Buysse, J., \& Van Huylenbroeck, G. (2011). The influence of subjective and objective knowledge on attitude, motivations and consumption of organic food. British Food Journal, 113(11), 1353-1378.

Agnew, S., \& Cameron-Agnew, T. (2015). The influence of consumer socialisation in the home on gender differences in financial literacy. International Journal of Consumer Studies, 39(6), 630-638.

Amin, H., Rahim Abdul Rahman, A., \& Ramayah, T. (2009). What makes undergraduate students enrol into an elective course? The case of Islamic accounting. International Journal of Islamic and Middle Eastern Finance and Management, 2(4), $289-304$.

Ateed, H., \& Ur Rehman, A. (2020). Determinants of bank choice in Afghanistan. Journal of Islamic Finance, 9(1), 61-75.

Chen, H., \& Volpe, R. P. (1998). An analysis of personal financial literacy among college students. Financial Services Review, 7(2), 107-128.

Chin, W.W. (2010). How to write up and report PLS analyses, In Vinzi, V.E., Chin, W.W., Henseler, J., and Wang, H. (eds.), Handbook of Partial Least Squares. (pp. 655-690). Berlin, Germany: Springer-Verlag.

Churchill Jr, G. A. (1979). A paradigm for developing better measures of marketing constructs. Journal of Marketing Research, 16(1), 64-73.

Danes, S. M. (1994). Parental perceptions of children's financial socialization. Financial Counseling and Planning, 5(1), 27-146.

Eniola, A. A., \& Entebang, H. (2017). SME managers and financial literacy. Global Business Review, 18(3), 559-576.

Fornell, C., \& Larcker, D.F. (1981). Evaluating structural equations models with unobservable variables and measurement error, Journal of Marketing Research, 18(1), 39-50.

Freedman, D., Pissani, R., \& Purves, R. (2002). Statistics (4th ed.).USA: W.W. Norton \& Company Inc.

Grable, J. E., \& Joo, S. (1998). Does financial education affect knowledge, attitudes, and behaviour? An empirical analysis. Personal Finances and Worker Productivity, 2(2), 213-220. 
Greenspan, A. (2002). Financial literacy: A tool for economic progress. The Futurist, 36(4), 37.

Hair, J. F., Black, W. C., Babin, B. J., Anderson, R. E., \& Tatham, R. (2006). Multivariate data analysis. Uppersaddle River. NJ USA: Prentice-Hall.

Haque, A. (2010). Islamic banking in Malaysia: A study of attitudinal differences of Malaysian customers. European Journal of Economics, Finance and Administrative Sciences, 18(18), 7-18.

Hayhoe, C. R., Leach, L., \& Turner, P. R. (1999). Discriminating the number of credit cards held by college students using credit and money attitudes. Journal of Economic Psychology, 20(6), 643-656.

Hira, T. K., Sabri, M. F., \& Loibl, C. (2013). Financial socialization's impact on investment orientation and household net worth. International Journal of Consumer Studies, 37(1), 29-35.

Hulland, J. (1999). Use of Partial Least Squares (PLS) in strategic management research: A review of four recent studies, Strategic Management Journal, 20(2), 195-204.

Ismail, S., Haron, H., Ismail, I., \& Vinten, G. (2007). Factors influencing auditors' acceptance of the practice review system. Asian Academy of Management Journal, 12(2), 57-82.

Jorgensen, B. L., \& Savla, J. (2010). Financial literacy of young adults: The importance of parental socialization. Family Relations, 59(4), 465-478.

Kim, K. (2003). Money attitudes and personal finance of college students. Journal of Consumption Culture, 6(3), 33-50.

Kimunduu, G., Erick, O., \& Shisia, A. (2016). A study on the influence of financial literacy on the financial performance of small and medium enterprises in Ruiru town, Kiambu County, Kenya. International Journal of Economics, Commerce and Management, IV (11), 416-433.

Kizza, J. (2019). Financial literacy and financial performance of small and medium enterprises in Uganda. International Journal of Research and Innovation in Social Science, III(X), 2454-6186.

Klapper, L.F., Lusard, A., \& Panos, G.A. (2013). Financial literacy and its consequences: Evidence from Russia during the financial crisis. Journal of Banking and Finance, 37(10), 3904-3923.

Lada, S., Harvey Tanakinjal, G., \& Amin, H. (2009). Predicting intention to choose halal products using the theory of reasoned action. International Journal of Islamic and Middle Eastern Finance and Management, 2(1), 66-76.

Lee, Y., \& Kozar, K.A. (2008). An empirical investigation of anti-spyware software adoption: A multi-theoretical perspective. Information and Management, 45(2), 109-119.

Manika, D., Gregory-Smith, D., \& Papagiannidis, S. (2018). The influence of prior knowledge structures on website attitudes and behavioural intentions. Computers in Human Behavior, 78, 44-58.

Miller, M., Godfrey, N., Levesque, B., \& Stark, E. (2009). The case for financial literacy in developing countries: Promoting access to finance by empowering consumers. World Bank, DFID, OECD e CGAP, http://www. oecd.org/dataoecd/35/32/43245359. $p d f$.

M-Yasin, M., Ramayah, T., Mohamad, O., \& Wah, L.L. (2009). The mediating effects of attitude towards parallel imports in consumer personality - Purchase intention linkage. Jurnal Pengurusan, 28, 103-123.

National SME Development Council (NSDC) (2013). Guideline for new SME definition. Retrieved on June 25, 2020, at https://www.exim.com.my/index.php/en/media-centre/announcement/item/guideline-for-new-sme-definition

Neagu, C. (2016). The importance and role of a small and medium-sized business. Theoretical and Applied Economics, XXIII(3), 331-338.

Preacher, K.K., \& Hayes, A.E. (2008). Asymptotic and resampling strategies for assessing and comparing indirect effects in multiple mediator models, Behaviour Research Methods, 40(3), 879-891.

\section{ACKNOWLEDGEMENT}

The authors would like to thank family members for moral support.

\section{DECLARATION CONFLICT OF INTEREST}

There is no conflict interest involved in the publication of this work. 


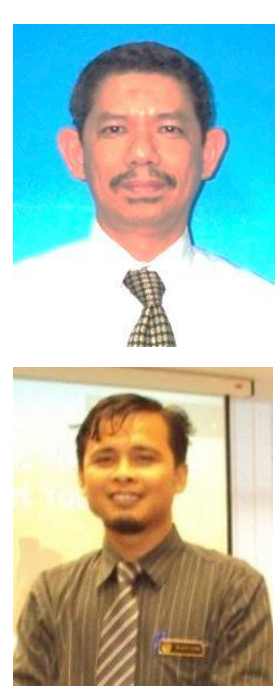

DZULJASTRI ABDUL RAZAK is an Associate Professor at the Department of Finance, Kulliyyah of Economics and Management Sciences, International Islamic University Malaysia, Malaysia. He earned his $\mathrm{PhD}$ in 2011 from Universiti Sains Malaysia in Islamic Banking and Finance. He teaches marketing, bank management, bank marketing, Islamic products and services and Islamic financial planning. His areas of interest are Islamic home financing, Islamic micro-credit, equity financing, personal finance, service quality in Islamic banking, maqasid al-Shariah and financial crisis from an Islamic perspective. He has published a number of articles in Review of Islamic Economics, International Journal of Islamic and Middle Eastern Finance and Management, Global Journal of Finance and Economics, JKAU Islamic Economics, Journal of Islamic Marketing and American Journal of Applied Sciences, to mention some.

HANUDIN AMIN is an Associate Professor at the Universiti Malaysia Sabah - Labuan International Campus. He teaches Islamic Accounting, Islamic Banking, Mutual Fund Management, Banking Management, Research Method, Issues in Islamic Finance, International Banking and Financial Statement Analysis, to name a few. His areas of interest are Islamic banking, Islamic accounting and Islamic marketing. He earned his PhD in 2015 from the IIUM Institute of Islamic Banking and Finance (IIi BF) International Islamic University Malaysia, Kuala Lumpur, Malaysia. 